Özbay, M.-Benzer, A. (2013). Türkçe öğretmeni adaylarının bilgi okuryazarlığı üzerine bir değerlendirme. Ana Dili Eğitimi Dergisi, 1(3), 29-40.

Ana Dili Eğitimi Dergisi
Journal of Mother Tongue Education
ADED - JOMTE
www.anadiliegitimi.com

\title{
Türkçe Öğretmeni Adaylarının Bilgi Okuryazarlı̆ı̆ Üzerine Bir Değerlendirme
}

\author{
Murat Özbay* \\ Ahmet Benzer $^{* *}$
}

\begin{abstract}
Özet
Küreselleşme ile birlikte gerçek bilgiyi elde etmenin ve yorumlamanın önemi her geçen gün artmış, bireylerin yazılı veya elektronik kaynaklarda bilgiyi etkin olarak tüketmeleri ve sentezleyerek yeni ve bilimsel bilgiler üretmeleri istenir olmuştur. Böylece bilgi, bütün milletler için ortak bir havuzda toplanmış ve ona ulaşmasını ve kullanmasını bilenlerin elinde hızlı çoğalmıştır. Böyle bir dönemde bilgiyi çarpıtmadan oluşturmak ve gerçek bilgiye ulaşmak için bireylerin bilgi okuryazarı olmaları gerekmektedir. Bireylerin bilgi okuryazarlı̆ını geliştirme uğraşı Türkçe öğretimi kapsamındaki anlama ve anlatma becerilerine yönelik kazanımlar ile desteklenmektedir. Bu bağlamda araştırmanın amacı Türkçe öğretmen adaylarının bilg okuryazarlığı düzeylerine sınıf seviyesi ve cinsiyete bağlı olarak incelemek ve Türkçe öğretmen adaylarının bilgi okuryazarlığına sahip olmada zorlandıkları etmenleri tespit etmektir. Araştırma tarama modeline göre tasarlanmış ve verilerin toplanması için öğretmen adaylarına yönelik geliştirilen bilgi okuryazarlığı anketi kullanılmıştır. Araştırma sonucunda Türkçe öğretmen adaylarının bilgi okuryazarlıkları düzeyleri sınıf seviyesine göre farklılık göstermiş olup cinsiyete göre bir farklıık bulunmamıştır.
\end{abstract}

Anahtar Kelimeler: bilgi okuryazarlı̆̆ı, Türkçe eğitimi, okuryazarlık.

\section{An Evaluation of Information Literacy Level of Turkish Pre-Service Teacher}

\begin{abstract}
With globalization, the importance of obtaining and interpreting true information has become bigger day by day, and individuals are expected to consume information effectively and produce new and scientific information by interpreting the information in written or electronic sources. So, information has accumulated in a common pool for all the nations, and it has proliferated in the hands of those who know how to reach and use it. In such an era, for producing information without distorting and for getting true information individuals have to be information literate. Efforts in improving individuals' information literacy are supported with reading and telling skills which are in the extent of Turkish language education. Within this context, the goal of this study is to examine literacy levels of Turkish language teachers with regards to grade and gender and to define factors which they have difficulty in having information literacy. Study has been designed according to survey method and for gathering information; literacy questionnaire that is developed for teacher candidates has been implemented. Study has shown that Turkish language teacher candidates' information literacy levels bare difference according to grades, however, no difference according to gender has been encountered.
\end{abstract}

Keywords: Information literacy, Turkish education, literacy.

\footnotetext{
*Prof. Dr., Gazi Üniversitesi, Eğitim Fakültesi, Türkçe Eğitimi Bölümü, Ankara. E-posta: mozbay@gazi.edu.tr.

Yrd. Doç. Dr., Marmara Üniversitesi, Eğitim Fakültesi, Türkçe Eğitimi Bölümü, İstanbul. E-posta: abenzer@marmara.edu.tr.
} 


\section{Giriş}

Çeşitli bilim dallarına ait 32 farklı alanından söz edilen okuryazarlık kavramının (Snavely ve Cooper 1997: 12) kökenleri çok eskiye dayanmaktadır. Bruce (1998)'a göre okuryazarlık kavramı ilkel sembol sisteminden görsel okuryazarlığa doğru zaman içerisinde değişime uğramıştır. Bilgi okuryazarlığı ise bir şemsiye kavram olarak bütün okuryazarlık alanlarını kapsayıcı bir nitelik taşımaktadır (Breivik ve Ford 1993: 98). Bilgi okuryazarlı̆ı kavramı ilk defa 1974 yılında Paul Zurkowski tarafından (Doyle 1994: 5; Spitzer, Eisenberg ve Lowe 1998: 22; Owusu-Ansah 2005: 367) kullanılmış ve günümüze kadar da genişleyerek kavram daha da önem kazanmıştır. Nitekim son dokuz ayda (Eylül 2012-Haziran 2013) Türk dil kurumunun sitesinde 'bilgi okuryazarlığı' kavramının yaklaşık olarak 24 milyon kez aranması dikkate değerdir.

Bilgi okuryazarlığı, basılı bilgi kaynaklarına sayıları hızla artan elektronik kaynakların da eklenmesiyle bilginin katlanarak arttığı ve bireylerin başarısının, ne kadar etkin ve becerikli bilgi tüketicileri ve üreticileri olduklarına bağı olarak belirlendiği günümüz dünyasında, kazandırılması kaçınılmaz bir beceri olmuştur (Erdem ve Akkoyunlu 2002). Bawden (2001: 218)'e göre bilgi okuryazarlığı anket ve çözümleme yoluyla bilginin ele alınması ve tanımlanmasıdır.

Breivik (2000)'e göre bilgi okuryazarlığının anahtar kelimesi yaşam boyu öğrenen bireylerin yetişmesidir. Bilgi okuryazarı bireylerin en önemli özelliği bilgiyi nasıl kullanacaklarını bilmeleridir (Hancock 1993). Kızıl (2007: 10)'a göre bilgi okuryazarı olan birey; bilmeyi arzu eden, soruları formüle edebilen, analitik düşünme becerilerine sahip olan, araştırma yöntemlerini belirleyebilen ve sonuçların değerlendirilmesinde eleştirel olabilen kişidir. Böylece bilgi okuryazarlığıyla bireylerin pasif konumdan bilgiyi işleyen ve buldukları bilgiyi olduğu gibi kabul etmeyen etkin katılımcı konumda olması amaçlanmaktır.

Doyle (1994: 2-3) da bilgi okuryazarı bir bireyde bulunması gereken özellikleri şöyle belirlemiştir:

1. Doğru ve tam bilgi olduğuna karar verebilme

2. İhtiyacı olan bilgiyi tanıyabilme

3. Ihtiyaç duyduğu bilgiyi bulmaya yönelik sorular oluşturabilme

4. Olası bilgi kaynaklarını tanıma

5. Başarılı araştırma stratejisi geliştirme

6. Bilgisayar teknolojisinin dâhil olduğu bilgi kaynaklarına ulaşabilme

7. Bilgiyi değerlendirme 
8. Pratik uygulamalar için bilgiyi düzenleme

9. Var olan bilgiyle yeni bilgiyi bütünleştirme

10. Problem çözme ve eleştirel düşünerek bilgiyi kullanma

Yukarıda verilen bu özellikler bireyin bilgiyi edinme sürecinde pasif olmadığının ve aktif olarak katılımlı/etkileşimli olarak yer aldığını göstermesi bakımından önemlidir. Kurbanoğlu ve Akkoyunlu (2007)'ya göre bu durum bir yandan öğretmenlerin sahip olmaları gereken becerileri artırırken, diğer yandan öğrencilerini değişen dünyaya hazırlayabilmek için öğretmenlerin söz konusu değişiklikleri yakından izleyerek bu değişikliklere ayak uydurmalarını zorunlu hâle getirmektedir.

Snavely ve Cooper (1997: 9) ve Bruce (2003) bilgi okuryazarlığı eğitim ortamında, evde, işte, okulda ve okul dışındaki öğrenme ortamlarında karar verme, problem çözme ve öğrenme için bilginin kullanımı, düzenlenmesi, değerlendirilmesi ve kabul etme becerisine sahip bireylerin yetiştirilmesini amaçlar. Kurbanoğlu ve Akkoyunlu (2007)'e göre bilgi okuryazarı öğretmenler, öğrencileri için en uygun kaynakları seçip kullanabilme gibi pek çok sebep dolayısıyla öğretmen eğitimini bilgi okuryazarlığını içerecek şekilde geliştirmek gerekli hâle gelmiştir.

Snavely ve Cooper (1997: 9)'a göre bilgi okuryazarı öğrencilerin öğrenme süreci içinde aşağıdaki becerilere sahip olması gerekir:

1. Ne zaman bilgiye ihtiyaç duyduğunu bilme,

2. Ele alınan problem ya da konu için gerekli olan bilgileri tanımlayabilme,

3. Gerekli bilgileri bulma,

4. Bilgileri değerlendirme,

5. Bilgileri düzenleme,

6. Ele alınan veya ele alınması muhtemel problemler karşısında bilgiyi etkili bir biçimde kullanma becerilerine sahip olurlar.

Türkçe Dersi Öğretim Programı́yla (2006) dinlediklerini, izlediklerini ve okuduklarını anlayan; duygu, düşünce ve hayallerini anlatan; eleştirel ve yaratıcı düşünen, sorumluluk üstlenen, girişimci, çevresiyle uyumlu, olay, durum ve bilgileri kendi birikimlerinden hareketle araştırma, sorgulama, eleştirme ve yorumlamayı alışkanlık hâline getiren, estetik zevk kazanmış ve millî değerlere duyarlı bireyler yetiştirilmesi amaçlanmıştır. Bu amaçlar içerisinde özellikle eleştirel ve yaratıcı düşünen, olay, durum ve bilgileri kendi birikimlerinden hareketle araştırma, sorgulama, eleştirme ve yorumlamayı alışkanlık hâline getiren maddesi bilgi okuryazarlığı becerisine sahip bireylere atıfta bulunmaktadır. Bütün bu kazanımları öğrencilerin edinmesini sağlayacak olan Türkçe öğretmen adaylarının da bu 
becerilere sahip olması gerekmektedir. Bu doğrultuda araştırmanın amacı Türkçe öğretmen adaylarının bilgi okuryazarlığı düzeylerine sınıf seviyesi ve cinsiyete bağlı olarak incelemek ve Türkçe öğretmen adaylarının bilgi okuryazarlığına sahip olmada zorlandıkları etmenleri tespit etmektir. Araştırmanın alt problemleri şu şekilde oluşturulmuştur:

1. Türkçe öğretmenliği öğrencilerinin bilgi okuryazarlıkları sınıf seviyesine göre anlamlı farklılık göstermekte midir?

2. Türkçe öğretmenliği öğrencilerinin bilgi okuryazarlıkları cinsiyete göre anlamlı farklılık göstermekte midir?

3. Türkçe öğretmenliği öğrencileri bilgi okuryazarlığı alt boyutlarından en çok ve en az hangi maddelerde zorlanmaktadırlar?

\section{Yöntem}

Bu çalışmada tarama modeli kullanılmıştır. Tarama yöntemi geçmişte ya da hâlen var olan bir durumu var olduğu şekliyle betimlemeyi amaçlayan araştırma yaklaşımıdır. Araştırmaya konu olan olay, birey ya da nesne kendi şartları içerisinde ve olduğu gibi tanımlanmaya çalışılır (Karasar, 2009).

\section{Araştırma Grubu}

Örneklem grubu olarak İstanbul ilindeki Marmara Üniversitesinin 2011-2012 eğitim öğretim yılında Türkçe öğretmenliği bölümünde öğrenim gören 132 öğrenci seçilmiştir. Çalışmanın evreni ise İstanbul'daki üniversitelerin Türkçe öğretmenliği bölümündeki öğrencilerden oluşmaktadır. Örneklem grubunun özelliklerine aşağıda yer verilmiştir:

Tablo 1: Katılımcılarım özellikleri

\begin{tabular}{llllll}
\hline & Kız & \multicolumn{3}{c}{ Erkek } & Toplam \\
& Mevcut & Yüzde & Mevcut & Yüzde & \\
1. sınıf & 28 & 85 & 5 & 15 & $\mathbf{3 3}$ \\
2. sınıf & 20 & 56 & 16 & 44 & $\mathbf{3 6}$ \\
3. sınıf & 11 & 42 & 15 & 58 & $\mathbf{2 6}$ \\
4. sınıf & 13 & 35 & 24 & 65 & $\mathbf{3 7}$ \\
Toplam & $\mathbf{7 2}$ & & $\mathbf{6 0}$ & & $\mathbf{1 3 2}$ \\
\hline
\end{tabular}

\section{Verilerin Toplanması ve Değerlendirilmesi}

Çalışmada öğrencilerin bilgi okuryazarlıkları Aldemir (2004) tarafından geliştirilen "Bilgi Okuryazarlığı Ölçeği” ile toplanmıştır. Tümü olumlu yargı içeren 35 maddeden oluşan ölçek; bilgi 
okuryazarlığı tanımları, standartları ve bilgi problemi çözme aşamaları ı̧ı̆̆ında hazırlanmış ve bilgi gereksiniminin tanımlanması, bilginin aranması, elde edilmesi, kullanılması, iletilmesi ve sürecin değerlendirilmesi basamaklarını içermektedir. Ölçekte öğrencilerden maddelerde verilen ifadeleri söz konusu eylemi gerçekleştirirken deneyimlerindeki zorlanma düzeyine göre derecelendirmeleri istenmiştir. Bu amaçla 5'li likert tipinde hazırlanan ölçeğin güvenirlik katsayısı cronbachalfa 89 olarak bulunmuştur. Bu çalışmada 132 kişilik örneklem grubunu oluşturan öğrencilerden elde edilen verilerden hareketle iç tutarlık kat sayısı cronbachalfa .90 olarak hesaplanmıştır.

Çalışmada veriler nicel olarak SPSS 17.00 programıyla değerlendirilmiştir. Değerlendirmede kullanılan testler, verilerin normal dağılımda olup olmadıklarına göre belirlenmiştir. Buna göre verilerin normal dağılım Kolmogorov-Smirnov değerleri tablo 2'de verilmiştir.

Tablo 2: Sınıf düzeyinde dağılım

\begin{tabular}{llll}
\hline & $N$ & $Z$ & $p$ \\
1. sınıf & 33 &, 501 &, 963 \\
2. sınıf & 36 &, 792 &, 558 \\
3. sınıf & 26 &, 712 &, 690 \\
4. sınıf & 37 &, 455 &, 986 \\
Kız öğrenciler & 72 &, 465 &, 982 \\
Erkek öğrenciler & 60 &, 751 &, 625 \\
\hline
\end{tabular}

Türkçe öğretmenliği öğrencilerinin her bir sınıf düzeyi ve cinsiyete göre verilerinin normal dağılımda oldukları görülmektedir ( $p$ değerleri > 0.05). Buradan hareketle sınıf düzeylerinin bilgi okuryazarlık puanlarının kendi içlerinde ikili karşılaştırmalarında ve cinsiyete göre yapılan karşılaştırmada ilişkisiz gruplar t testi kullanılmıştır.

\section{Bulgular}

\section{Sınıf Seviyelerine Göre Yapılan Karşılaştırma}

"Türkçe öğretmenliği öğrencilerinin bilgi okuryazarlıkları sınıf seviyesine göre anlamlı farklılık göstermekte midir?" alt problemine çözüm bulabilmek için yapılan değerlendirmede aşağıdaki bulgular elde edilmiştir. 
Tablo 3: Öğrencilerin bilgi okuryazarlıklarının sınıf düzeyine göre karşılaştırılmasıyla ilgili t-testi bulguları

\begin{tabular}{|c|c|c|c|c|c|}
\hline Grup & $n$ & Ortalama & $\begin{array}{l}\text { Standart } \\
\text { sapma }\end{array}$ & $T$ & $p$ \\
\hline 1. $\sin I f$ & 33 & 112,515 & 16,266 & \multirow{2}{*}{$-2,834$} & \multirow{2}{*}{0,006} \\
\hline 2. sinif & 36 & 123,806 & 16,767 & & \\
\hline 1. $\sin I f$ & 33 & 112,515 & 16,266 & \multirow{2}{*}{$-3,227$} & \multirow{2}{*}{0,002} \\
\hline 3. sinif & 26 & 127,000 & 18,150 & & \\
\hline 1. $\sin I f$ & 33 & 112,515 & 16,266 & \multirow{2}{*}{$-3,561$} & \multirow{2}{*}{0,001} \\
\hline 4. $\sin I f$ & 37 & 125,946 & 15,153 & & \\
\hline 2. $\sin I f$ & 36 & 123,806 & 16,767 & \multirow{2}{*}{$-0,715$} & \multirow{2}{*}{0,477} \\
\hline 3. sinıf & 26 & 127,000 & 18,150 & & \\
\hline 2. $\sin I f$ & 36 & 123,806 & 16,767 & \multirow{2}{*}{$-0,573$} & \multirow{2}{*}{0,569} \\
\hline 4. $\sin I f$ & 37 & 125,946 & 15,153 & & \\
\hline 3. sinıf & 26 & 127,000 & 18,150 & \multirow{2}{*}{0,250} & \multirow{2}{*}{0,803} \\
\hline 4. sinıf & 37 & 125,946 & 15,153 & & \\
\hline
\end{tabular}

Tablo 3'te 1. sınıf öğrencilerinin bilgi okuryazarlıklarının diğer sınıflara göre anlamlı bir farkla düşük çıktığı görülmektedir $\left(p_{1-2}, p_{1-3}, p_{1-4}<0,05\right)$. İkinci, üçüncü ve dördüncü sınıfların bilgi okuryazarlığı ölçeğinden aldıkları puanlar arasında ise anlamlı bir fark bulunmamıştır ( $p$ değerleri>0,05).

\section{Cinsiyete Göre Yapılan Karşılaştırma}

"Türkçe öğretmenliği öğrencilerinin bilgi okuryazarlıkları cinsiyete göre anlamlı farklılık göstermekte midir?" alt problemine çözüm bulabilmek için yapılan değerlendirmede aşağıdaki bulgular elde edilmiştir.

Tablo 4: Öğrencilerin bilgi okuryazarlıklarının sınıf düzeyine göre karşılaştırılmasıyla ilgili t-testi bulguları

\begin{tabular}{lccccc}
\hline Cinsiyet & $n$ & Ortalama & $\begin{array}{l}\text { Standart } \\
\text { sapma }\end{array}$ & $t$ & $p$ \\
\hline Kız öğrenciler & 72 & 120,625 & 16,895 & $-1,157$ &, 251 \\
Erkek öğrenciler & 60 & 124,117 & 17,683 & & \\
\hline
\end{tabular}


Tablo 4'te kız öğrencilerin bilgi okuryazarlığı ölçeğinden aldıkları ortalama puan ile erkek öğrencilerin ortalama puanları arasında anlamlı bir fark tespit edilmemiştir $(p>0,05)$. Buradan hareketle Türkçe öğretmenliği öğrencilerinin bilgi okuryazarlık seviyelerinin cinsiyete göre değişmediği söylenebilir.

\section{Bilgi Okuryazarlığının Alt Basamaklarında Zorlanma Dereceleri}

"Türkçe öğretmenliği öğrencileri bilgi okuryazarlığı alt boyutlarından en çok ve en az hangi maddelerde zorlanmaktadırlar?" alt problemi kapsamında elde edilen bulgulara tablo 5 ve tablo 6 'da yer verilmiştir.

Tablo 5: En çok zorlanılan maddeler

\begin{tabular}{|c|c|c|}
\hline Soru & $\begin{array}{l}\text { Genel } \\
\text { ortalama }\end{array}$ & Anket maddesi \\
\hline 9. soru & 3,07 & $\begin{array}{l}\text { Bilgiye erişimi sağlayan indeksleri ve elektronik veri tabanlarını } \\
\text { seçmekte ve kullanmakta }\end{array}$ \\
\hline 20. soru & 3,07 & $\begin{array}{l}\text { Web kaynaklarını güncellik, güvenirlik, doğruluk, tarafsızlık gibi } \\
\text { unsurlar açısından değerlendirmekte }\end{array}$ \\
\hline 30. soru & 3,10 & Ödev/araştırma sonuçlarımı sözlü olarak sunmakta \\
\hline 1. soru & 3,14 & $\begin{array}{l}\text { Ödev/Araştırma konusunu kendim belirlemek durumunda } \\
\text { kaldığımda }\end{array}$ \\
\hline 2. soru & 3,23 & $\begin{array}{l}\text { Ödev/Araştırma konusuna ilişkin bilgi gereksinimimi } \\
\text { tanımlamakta }\end{array}$ \\
\hline 31. soru & 3,33 & $\begin{array}{l}\text { Araştırma sonuçlarımı yazılı olarak (ödev, rapor, makale vb.) } \\
\text { sunmakta }\end{array}$ \\
\hline
\end{tabular}

Tablo 5 incelendiğinde öğrencilerin genel anlamda kendi başlarına yapmaları gereken işlerde oldukça zorlandıkları görülmüştür. Kendi başlarına karar verme ve hareket etmede karşılaşılan zorluklara ek olarak bilginin sunumu aşamasın da birtakım zorluklar yaşadıkları tespit edilmiştir. 
Tablo 6: Daha az zorlanılan maddeler

\begin{tabular}{|c|c|c|}
\hline Soru & $\begin{array}{l}\text { Genel } \\
\text { ortalama }\end{array}$ & Anket maddesi \\
\hline 10. soru & 3,96 & $\begin{array}{l}\text { Web arama motorlarını (google, altavista, arabul gibi) } \\
\text { kullanmakta }\end{array}$ \\
\hline 22. soru & 3,85 & $\begin{array}{l}\text { Okuduğum bilgi kaynakları arasındaki benzer ve farklı noktaları } \\
\text { belirlemekte }\end{array}$ \\
\hline 24. soru & 3,78 & Önceki bilgilerimle yeni elde ettiğim bilgiyi ilişkilendirmekte \\
\hline 23. soru & 3,72 & Elde ettiğim bilgiyi yorumlamakta \\
\hline 33. soru & 3,72 & $\begin{array}{l}\text { Bilginin iletiminde/sunumunda uygun teknolojiyi kullanmakta } \\
\text { (powerpoint slaytları, video, word dosyası gibi) }\end{array}$ \\
\hline 35. soru & 3,67 & $\begin{array}{l}\text { Bilgi ile ilgili faaliyetlerimden (bilgiyi arama, bulma, kullanma, } \\
\text { iletme) ileriye yönelik dersler çıkartmakta }\end{array}$ \\
\hline 12. soru & 3,66 & $\begin{array}{l}\text { Bilgisayarla bilgi ararken tarih, dil ve tür gibi sınırlamalar } \\
\text { yapmakta }\end{array}$ \\
\hline 34. soru & 3,45 & $\begin{array}{l}\text { Yaptığım ödevleri/araştırmaları eleştirmekte (güçlü ve zayıf } \\
\text { yönlerini tanımlamakta) }\end{array}$ \\
\hline
\end{tabular}

Tablo 6 incelendiğinde öğrencilerin internette arama yapma ve teknoloji kullanımında daha az zorlandıkları görülmüştür.

\section{Tartışma ve Sonuç}

İ̧̧inde bulunduğumuz 21. yüzyıl bilgi çağı olarak adlandırılmakta olup bilgiye ulaşmanın çok kolay olduğu bir dönemdir. Günümüzde okuryazarlık yalnızca okuma ve yazmanın ötesinde salt bilgiyi kullanabilme becerisi anlamına genişlemiştir. Bugünün bireylerinden yalnızca bilgiye ulaşmaları değil, eleştirel okuma, gerekli ve gereksiz bilgileri ayıklayabilme; yani bilgiyi sentezleyebilme ve edindikleri bilgileri kullanabilme becerilerine sahip olmaları istenmektedir. Teknolojideki hızlı gelişmeler öğrencinin bireysel ve okul içindeki toplu çalışmalarında, hazırladıkları ödevlerinde ve etkinliklerinde büyük bir değişimi beraberinde getirmiştir. Öğrenci ile öğretmenin rolleri bu süreçte değişmiş ve artık öğretmen tek bilgi kaynağı konumundan öğrenci de edilgin alııı konumundan çıkmıştır.

Ölçekten alınabilecek en yüksek puan 175 iken araştırmada öğrencilerin bilgi okuryazarlı̆̆ı genel ortalaması 122,212 olarak bulunmuştur. Bu durumda Türkçe öğretmenliğinde okuyan öğretmen adaylarının bilgi okuryazarlık seviyeleri düşük olarak nitelendirilmiştir. Benzer biçimde Aldemir (2004: 130) öğretmen adayları üzerine yaptığı araştırmasında öğretmen adaylarının bilgi okuryazarlığı becerilerinin her yönüyle gelişmediğini tespit etmiştir. Kızıl (2007: 102) da öğrencilerin 
bilgi okuryazarlığı seviyelerini yetersiz olarak bulmuştur. Kurbanoğlu ve Akkoyunlu (2002) ise öğretmen adaylarının kendilerini bilgi okuryazarlığı becerileri açısından çok yeterli görmediklerini belirlemişlerdir.

Araştırma sonucunda öğrencilerin bilgi okuryazarlığı sınıf düzeyine göre 1 ve 2 . sınıflar arasında anlamlı farklılık göstermiştir. Türkçe eğitimi bölümü 2. sınıf öğrencilerinin akademik yazma ve düşünme becerilerine yönelik aldıkları 'Bilimsel Araştırma Yöntemleri' dersi Türkçe eğitimi kapsamında yazma becerilerinde kullanabilecekleri bazı teknikleri (alıntılama gibi) içinde barındırmaktadır. Bu sebeple öğrencilerin 2. sınıfta bilgi okuryazarlık seviyelerinin arttığı düşünülmektedir. Nitekim Aldemir (2004) de araştırmasında farklı bölümler arasında bilgi okuryazarlık düzeylerinin değiştiğini tespit etmiş ve bunu yüksek çıkan bölümlerde var olan 'araştırma yöntemleri' adı altındaki derse bağlamıştır. Araştırmanın ikinci alt problemi kapsamında Türkçe öğretmenliği öğrencilerinin bilgi okuryazarlıklarının cinsiyete göre değişmediği tespit edilmiştir. Benzer sonucu Kızıl (2007: 58)'ın çalışmasında da görmek mümkündür.

Öğrenciler en çok "Ödev/Araştırma konusunu kendim belirlemede" ve "Ödev/Araştırma konusuna ilişkin bilgi gereksinimimi tanımlamada" zorlandıklarını belirtmişlerdir. Hâlbuki lisans seviyesindeki bireylerin sınırlı sayıdaki bilgi kaynaklarının dışına çıkarak farklı kaynaklara ulaşabilmelerini ve aynı zamanda ulaştığı bilgileri eleştirel bir bakış açısıyla okuyabilme, yazabilme ve anlatabilme becerisini kazanmış olmaları beklenmektedir. Nitekim Rader (2002: 243) da artık yükseköğretime gelen bir bireyin kendi başına kütüphane hizmetlerini kullanabiliyor ve çeşitli bilgi kaynaklarını biliyor olması gerektiğini belirtmiştir.

Öğrencilerin en çok zorlandıkları maddelerden biri de ödevlerini sözlü sunmadır. Özellikle Türkçe Öğretimi Programı (2006)'ndaki konuşma etkinlik örneklerinde; birikimlerden, çeşitli görsel ve işitsel materyallerden yararlanma, düşüncelerini mantık akışı ve bütünlük içinde sunma, karşılaştırma yapma, sebep-sonuç ilişkisi kurma, sınıflandırma, değerlendirme, özetleme gibi anlamayı ve zihinsel becerileri geliştirici çalışmalara yer verilmiştir. Bu etkinlikler incelendiğinde öğrencilerin yalnızca bilgiyi aktaran değil aynı zamanda onu işleyen sınıflayabilen ve birbiriyle ilişki kurabilen olması istenmekte ve böylece bilgi okuryazarı bir öğrencide bulunması gereken özellikler ile sözlü anlatım becerilerine sahip özellikler örtüşmektedir.

Öğrenciler en az "Okuduğum bilgi kaynakları arasındaki benzer ve farklı noktaları belirlemekte" ve "Önceki bilgilerimle yeni elde ettiğim bilgiyi ilişkilendirmekte" zorlandıklarını ifade etmişlerdir. Bu sonuç Türkçe Öğretimi Programı (2006)'nda yer alan eleştirel okuma ve metinlerle ilişkilendirerek okuma becerisi ile yakından ilişkili olması bilgi okuryazarlığı konusunun Türkçe Öğretimi Programı (2006)'ndaki kazanımlarla uyumluluk göstermesi bakımından manidardır. 
Türkçe Öğretimi Programı (2006)'nda öğrencilerin sahip olması gereken temel beceriler olan Türkçeyi doğru, güzel ve etkili kullanma, eleştirel düşünme, yaratıcı düşünme, iletişim kurma, problem çözme, araştırma, karar verme, bilgi teknolojilerini kullanma, girişimcilik maddeleri aynı zamanda bilgi okuryazarı bir bireyde bulunması gereken özelliklerdir. Türkçe eğitimiyle bilgi okuryazarlığının birleşiminde öğrencilere kazandırılması gereken temel becerilerin içi farklı disiplinlerden gelen bilgiyle daha kullanışlı hâle geleceği düşünülmektedir. Örneğin Özbay ve Çelik (2013) Türkçe öğretmen adaylarının bilgisayar kullanma yeterlilikleri üzerine yaptıkları araştırmada öğretmen adaylarının düzeyleri orta olarak bulunmuştur. Bilgi okuryazarı olabilmenin anahtar kurallarından biri de bilgisayar teknolojisini iyi kullanabilmektir. Türkçe öğretmeni bilgisayarı iyi kullanabilirse çok farklı bilgi kaynaklarına ulaşabilir ve bunları iyi bir Türkçe ile öğrencileriyle paylaşabilir ve eleştirel okuma ve yazma becerileri ile bilgiyi anlayarak süzerek kullanabilir. Benzer biçimde öğrenciler en çok zorlandıkları ikinci madde olarak "Web kaynaklarını güncellik, güvenirlik, doğruluk, tarafsızlık gibi unsurlar açısından değerlendirmekte" maddesini vermişlerdir. Bu madde Doyle (1994)'nin bilgi okuryazarı bir bireyde bulunması gerekli maddeleri arasındaki ilk sırada yer alan 'doğru ve tam bilgi olduğunu karar verebilme' ve Türkçe Öğretimi Programı (2006)'nda yer alan temel becerilerden biri olan 'karar verme' maddeleri ile alakalı olup iki alanın birbiriyle pek çok madde üzerinde aynı değerleri savunduğunu göstermesi bakımından önemlidir.

Araştırma kapsamında şu önerilere yer verilmiştir:

1. Öğrencilerin bilgi okuryazarlığı seviyelerini artırmak için öğretim üyeleri tarafından araştırma ödevlerinin verilmesi büyük önem taşımaktadır. Bu yolla öğrencilerin hem kaynak tarama hem bilgileri derleme hem de yorumlama kabiliyetlerinin gelişmesi sağlanabilecektir.

2. Bilgi okuryazarlığı Türkçe Öğretimi Programı (2006)'nda öğrencilere kazandırılması gereken temel beceriler arasında yer almalıdır. Bilgi okuryazarlığının kazanımlarından bazılarına Türkçe anlama ve anlatım becerileri arasında yer verilmelidir. Özellikle yazma becerisinin kullanımında doğrudan ve dolaylı aktarımlar üzerinde bilgi aktarımı sağlanabilir.

3. Türkçe öğretmenleri performans ödevlerini değerlendirirken yalnızca ödevin Türkçeye uygunluğu bakımlarından değil aynı zamanda öğrencinin bilgi okuryazarı olup olmadığı; yani "Bilgiyi kullanabiliyor mu yalnızca aktaran görevinde mi, bilgiyi işleyebiliyor mu, cümlelerin hangisi ona ait hangisi alıntı?" kısımlarından da inceleyerek öğrencilerinin bilgi okuryazarı olmasını sağlamaya dönük eleştiriler yapmalıdır.

4. Türkçe eğitiminde yazma eğitimi kapsamında verilecek bilgi okuryazarlığı bilgisi ile öğrencilerin bilgiye ulaşma ve işleme becerilerini geliştirmek mümkün olabilecektir. Bu doğrultuda öğrencilerin ileride alanı ne olursa olsun Türkçe dersinde öğrendikleri bilgiler ile gerekli-gereksiz 
bilgileri ayıklayabilme, kendi cümleleri ile başkalarının düşünceleri arasında ayrım yapabilme ve kendini ifade edebilme ki bu Türkçe Öğretimi Programı (2006)'nda kendini yazılı olarak ifade etme alışkanlığı kazanma şeklinde yer almaktadır, becerilerini Türkçe dersi ile kazanmış olacaktır. Bu anlamda hem bilgi okuryazarlı̆ının hem de Türkçe eğitiminin içeriğinin genişletilmesi düşünülebilir.

\section{Kaynaklar}

Akkoyunlu, B. (2008). Bilgi okuryazarlığı ve yaşam boyu öğrenme, $8^{\text {th }}$ International Educational Technology Conference, Anadolu Üniversitesi, Eskişehir.

Aldemir, A. (2004). Öğretmen Adaylarının Bilgi Okuryazarlığı Düzeyleri Üzerine Bir Araştırma: Sakarya Üniversitesi Örneği. Ankara, Hacettepe Üniversitesi, Sosyal Bilimler Enstitüsü, Yüksek Lisans Tezi.

Bawden, D. (2001). Information and digital literacies; a rewiew of concepts, Journal of Documentation, LVII, 2, 218-259.

Breivik, P. S. (2000). Information literacy and life long learning: themagical partnership, http://bivir.uacj.mx/dhi/DoctosNaciolnter/INFORMATIONLITERACYANDLIFELONGLEARNING.htm.

Breivik, P. S. ve Ford, B. J. (1993). Promotinglearning in libraries through information literacy, American Libraries, XXIV, 1, 98-99.

Bruce, C. (2003). Seven faces of information literacy to wards inviting students in to new experiences, http://crm.hct.ac.ae/events/archive/2003/speakers/bruce.pdf.

Doyle, C. S. (1994). Information literacy in an information society: A concept for the information age. Syracuse, NY: ERIC.

Erdem, M. ve Akkoyunlu, B. (2002). Bilgi okuryazarlığı becerileri ve bu becerilerin ögrencilere kazandırılması için düzenlenecek öğrenme ortamlarının özellikleri. Journal of Qafqaz, 9, 125-132.

Hancock, V. E. (1993). Information LiteracyforLifelong Learning. http://www.libraryinstruction.com/information-literacy.html.

http://tdk.gov.tr/index.php?option=com_gts\&arama=gts\&guid=TDK.GTS.4f749cf2049f98.67561887*29 Mart 2012 tarihindeki erişimdir.

Karasar, N. (2009). Bilimsel Araştırma Yöntemi. Ankara: Nobel Yayınevi.

Kızıl, M.(2007). Yükseköğrenimde bilgi okuryazarlığı (Selçuk Üniversitesi örneği), Yüksek Lisans Tezi, Selçuk Üniversitesi Sosyal Bilimler Enstitüsü, Konya.

Kurbanoğlu, S. S. ve Akkoyunlu, B. (2002). Öğretmen Adaylarına Uygulanan Bilgi Okuryazarlığı Programının Etkililiği ve Bilgi Okuryazarlığı Becerileri ile Bilgisayar Öz-Yeterlik Algısı Arasındaki ïlişki. Hacettepe Üniversitesi Eğitim Fakültesi Dergisi, 22: 98-105.

Kurbanoğlu, S. S. ve Akkoyunlu, B. (2007). Öğretmen eğitiminde bilgi okuryazarlığının önemi, Uluslararası Öğretmen Yetiştirme Politikaları ve Sorunları Sempozyumu, Bakü, Azerbaycan. 
Lankshear, C.;Snyder, I. ve Green, B. (2000). Teachers and techno literacy: managing literacy, technology and learning in schools. Allen \& UnwinAcademic.

Milli Eğitim Bakanlığı. (2006). Ilköğretim Türkçe dersi öğretim programı ve kılavuzu (6-8. Sınıflar).Ankara: MEB Devlet Kitapları Müdürlüğü Yayını.

Owusu-Annah, E. K. (2005). Debating definitions of information literacy: enough is enough!, Emerald Group Publishing Limited, 54 (6), 366-374.

Özbay, M. ve Çelik, M. E. (2013). Türkçe Öğretmeni Adaylarının Bilgisayar Kullanma Yeterliklerine İlişkin Görüşlerinin Değerlendirilmesi. Ana Dili Eğitimi Dergisi, 1(1), 107-115.

Polat, C. (2005), Üniversitelerde kütüphane merkezli bilgi okuryazarlığı programlarının geliştirilmesi: Hacettepe Üniversitesi örneği, Doktora Tezi, Hacettepe Üniversitesi Sosyal Bilimler Enstitüsü, Ankara.

Rader, H. B. (2002) “Information literacy 1973-2002: a selected literatüre review.” Library Trends, 51(2), 242259.

Snavely, L. ve Cooper N. (1997). The Information Literacy Debate, TheJournal of Academic Librarianship, 23 (1), 9-13.

Spitzer, K. L.; Eisenberg Michael B. ve Lowe, C.A. (1998). Information Literacy: Essential Skills for the Information Age, Syracuse, New York: ERIC Clearing house on Information \& Technology. IR-104.

TDK (2013). Güncel Türkçe Sözlük. http://tdk.gov.tr/. 